\title{
Numerical Differential Protection of Power Transformer using Innovative Algorithm
}

\author{
Pooja Dudhal, H.B.Chaudhari, Vipin Mishra, Bhanwar Lal Bishnoi
}

\begin{abstract}
This paper presents a new innovative algorithm for Numerical Differential Relay design of transformer. Fault information is critical for operating and maintaining power networks. This algorithm provides accurate performance for transformer by which is independent of system conditions such as: External fault, Inrush current, CT saturation. Locating transformer faults quickly and accurately is very important for economy, safety and reliability point of view. Both fault-detection and protection indices are derived by using Numerical Differential Relay algorithm design of transformer. The embedded based differential and operating current measurement device is called numerical differential relay is among the most important development in the field of instantaneous fault operation.

Numerical relay provides measurement of differential current and operating current at power transformer above 5MVA in substation. Simulation studies are carried out using MATLAB Software show that the proposed scheme provides a high accuracy and fast relay response in internal fault conditions.

Current transformers form an important part of protective systems. Ideal Current Transformers (CTs) are expected to reflect the primary current faithfully on the secondary side. Under conditions the CT saturates, and hence it cannot reproduce the primary current faithfully. This paper deals with simulation methods for determining CT performance under different factor. A Simulink model has been developed to observe CT response under steady state w.r.t Burden, Turns ratio, Asymmetrical current, Hysteresis conditions. Thus, it is now possible to evaluate the CT performance under these factors.
\end{abstract}

\section{Index Terms: DC offset, FFT, Hysteresis, Burden}

\section{INTRODUCTION}

Differential protection is protection of equipment from internal faults (L-G, L-L, L-L-L etc) within the equipment and it does not operate for external or through faults. Protection against internal faults which are identified by comparing the electrical condition at the terminal of electrical equipment to be protected. It measures the Phasor difference of secondary current from two CT's connected at equipment end connection. This is most sensitive \& effective methods of protection of electrical equipment from internal faults which operate instantaneously. This principle of the protection is capable of detecting small magnitude of differential current (which should be zero ideally for normal operation). Over current or distance type relay are non-unit type (which is not confined to protection of particular power plant or substation) system protection which discriminates by virtue of time

Revised Manuscript Received on July 22, 2019.

Pooja Dudhal, Electrical Department, VJTI, Mumbai, India

Prof. H. B.Chaudhari, Electrical Department, VJTI, Mumbai, India

Vipin Mishra, EDDC Department, L\&T Electrical \& Automation, Mumbai,India

Bhanwar Lal Bishnoi, EDDC Department, L\&T Electrical \& Automation, Mumbai,India grading. They are comparatively simple, cheap \& do not require pilot wire circuit, but their fault clearance time is too slow for circuit operating at $33 \mathrm{Kv}$ or above. So for expensive equipment such as large generator, transformer $\&$ motor, over current and distance protection may not be suitable for fast operation of these devices during fault condition. Differential scheme inherently discriminate without use of time grading \& fast in fault clearance. Also, for equipment transformer, generator, bus, motor are at one geographical location where CT \& relay can be directly interconnected through the pilot wire. For EHV/ UHV transmission line, where terminals \& $\mathrm{CT}$ are widely separated by distance. Practically impossible to use differential protection relay.

Why transformer differential even it has many protections The faults occur inside the insulating oil can be detected by Buchholz relay. When any fault occurs in the transformer but not in the oil then it cannot be detected by Buchholz relay. The flash over takes place at the bushings are not adequately covered by Buchholz relay. Differential relays can detect such type of faults. Moreover, Buchholz relay is provided in transformer for detecting any internal fault in the transformer but Differential Protection scheme detects the same in faster way.

\section{ELECTROMECHANICAL \& NUMERICAL RELAY COMPARISION}

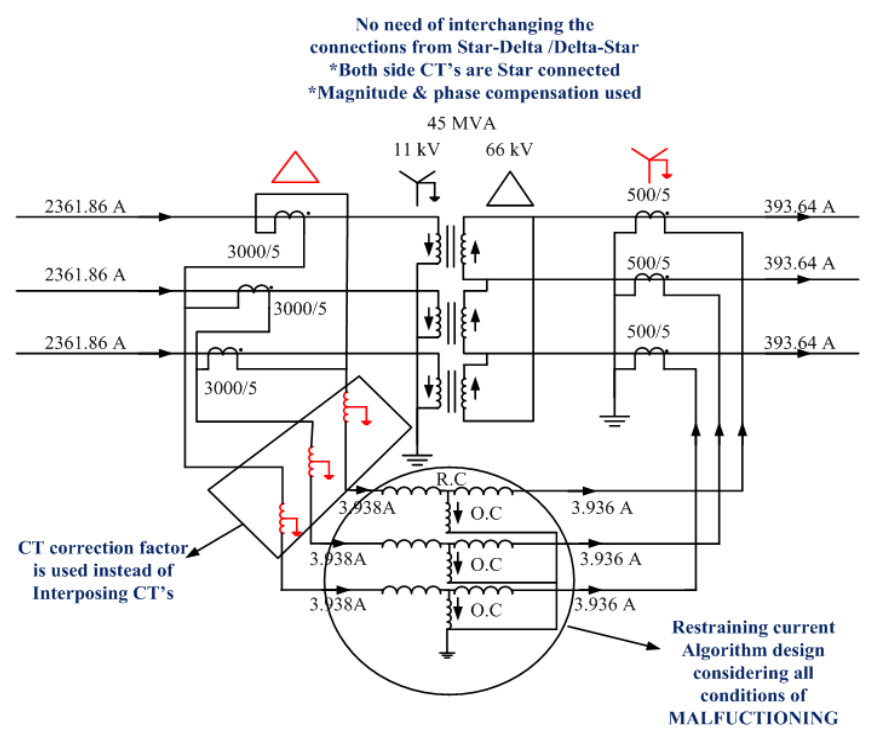

Fig.1.Comparision of Numerical relay with electromechanical relay. 
Features:

- Star connected CT on both side of transformer

- CT saturation is avoid by providing high resistor on neutral side of transformer called metrosil

- Time of accuracy isn't temperature dependent(i.e. its very fast operating)

- Fault disturbance recording, parameter setting is possible

- Requirement of draw out isn't required.

- Vibration proof

III. ChallengeS OF NUMERICAL DIFFERENTIAL PROTECTION

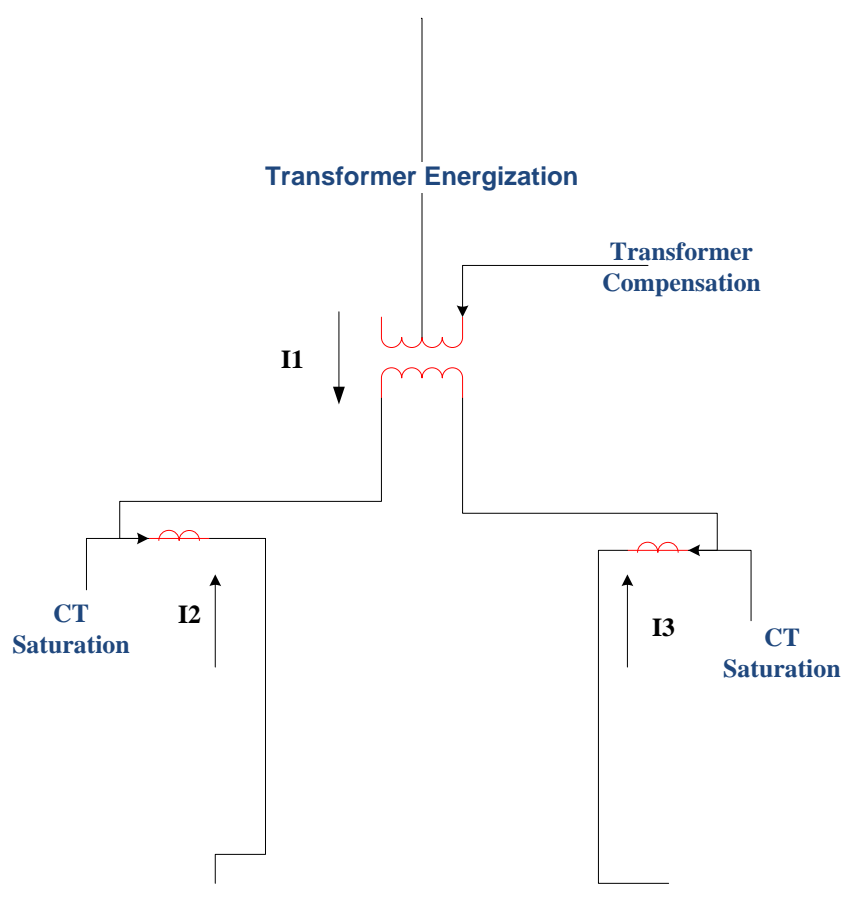

Fig.2.Numerical Differential protection challenges

\section{TRANSFORMER ENERGIZATION}

Under normal steady state conditions, the magnetizing current associated with the operating flux of transformer is relatively small (usually less than $1 \%$ of rated current). However, if a transformer winding is energized at a voltage zero, with no remnant flux, the flux level during the first voltage cycle ( $2 \mathrm{x}$ normal max. flux) will result in core saturation of transformer and in a high, non-sinusoidal magnetizing current waveform.

The magnetizing inrush current have a high percentage of second harmonic

If Inrush Restraint setting is set to Restraint

Additional bias $=\operatorname{Ih}(2)$ Multiplier $* 1.414 *$ largest 2 nd harmonic current.
- No interposing CT
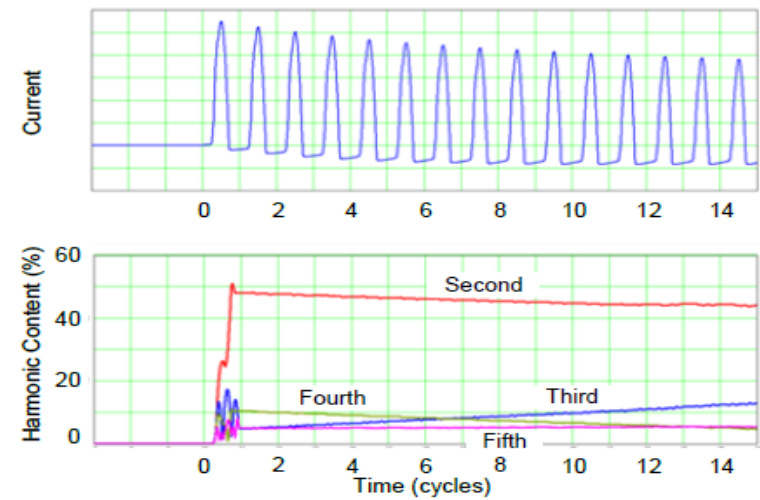

Fig.3.Transformer terminal phase current during energization (top) and the percentage harmonic content of the phase current during this time period(bottom)

Analysis of a typical magnitude inrush current wave shows (fundamental $=100 \%$ )

\begin{tabular}{|l|l|l|l|l|l|l|}
\hline DC & $\begin{array}{l}\text { 2nd } \\
\mathrm{H}\end{array}$ & 3 rd H & $\begin{array}{l}\text { 4th } \\
\mathrm{H}\end{array}$ & 5th H & 6 th H & $\begin{array}{l}\text { 7th } \\
\mathrm{H}\end{array}$ \\
\hline $55 \%$ & $63 \%$ & $\begin{array}{l}26.8 \\
\%\end{array}$ & $\begin{array}{l}5.1 \\
\%\end{array}$ & $4.1 \%$ & $3.7 \%$ & $\begin{array}{l}2.4 \\
\%\end{array}$ \\
\hline
\end{tabular}

Case study :

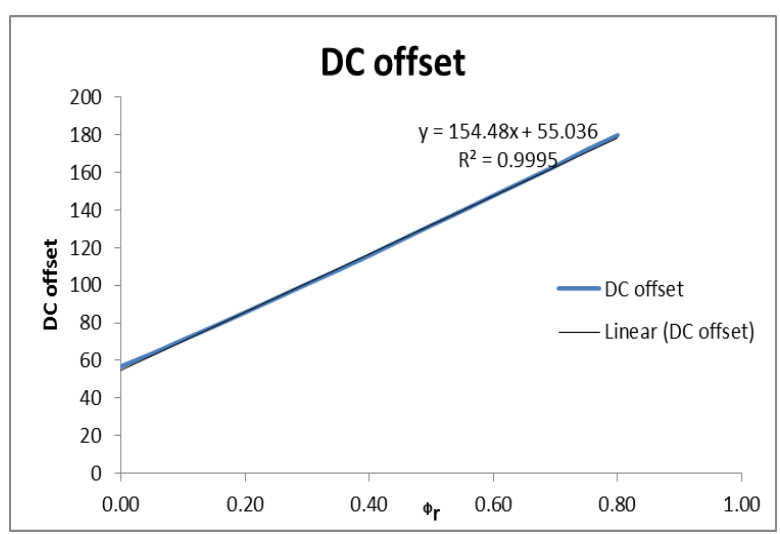

Fig.4.DC offset vs Remenence flux

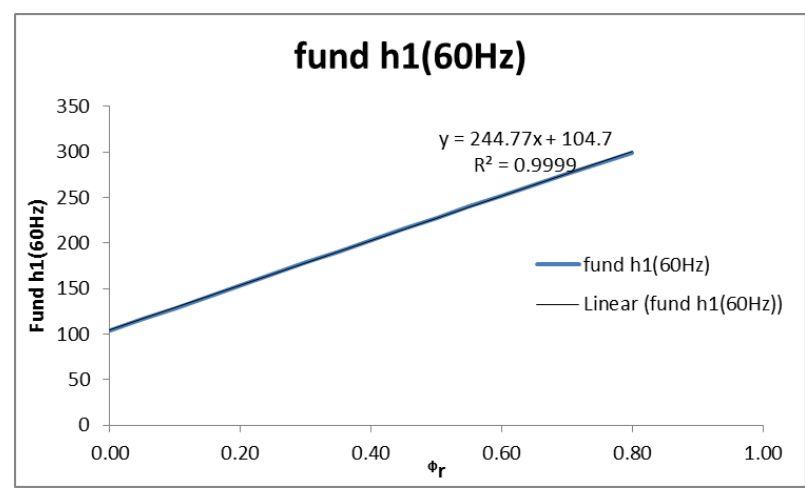

Fig.5.Fundamental frequency componenet vs Remenence flux

Published By: 
then decrease, also for 2nd harmonic the change is not in

\begin{tabular}{|c|c|c|c|c|}
\hline$\phi \mathbf{r}$ & DC offset & $\begin{array}{l}\text { fund } \\
\text { h1 }(60 \mathrm{~Hz})\end{array}$ & h2(120Hz) & h3(180Hz) \\
\hline 0.00 & 56.69 & 104.14 & 75.23 & 47.26 \\
\hline 0.05 & 63.68 & 116.36 & 83 & 50.45 \\
\hline 0.10 & 70.78 & 128.67 & 90.49 & 53.09 \\
\hline 0.15 & 78.07 & 141.11 & 97.69 & 55.13 \\
\hline 0.20 & 85.49 & 153.61 & 104.55 & 56.59 \\
\hline 0.30 & 100.52 & 178.52 & 117.2 & 58 \\
\hline 0.35 & 108.1 & 190.87 & 122.97 & 58.01 \\
\hline 0.40 & 115.84 & 203.27 & 128.35 & 57.48 \\
\hline 0.45 & 123.65 & 215.6 & 133.32 & 56.47 \\
\hline 0.50 & 131.56 & 227.9 & 137.86 & 55 \\
\hline 0.55 & 139.58 & 240.14 & 141.96 & 53.07 \\
\hline 0.60 & 147.51 & 252.13 & 145.68 & 50.91 \\
\hline 0.70 & 163.63 & 275.82 & 151.72 & 45.43 \\
\hline 0.75 & 171.85 & 287.52 & 153.99 & 42.1 \\
\hline 0.80 & 180.04 & 298.96 & 155.81 & 38.59 \\
\hline
\end{tabular}
linear proportion.so for distinguish the behavior of inrush we can use 2 nd harmonics data as compare to others.

\section{CT SATURATION}

A protection Current transformer should saturate at high inrush or magnetizing current to allow a accurate measurement of the fault current by the protection relay whose operating threshold can be very high. Current transformers are expected to have to withstand high overcurrent

\section{CT EQUIVALENTCIRCUIT}

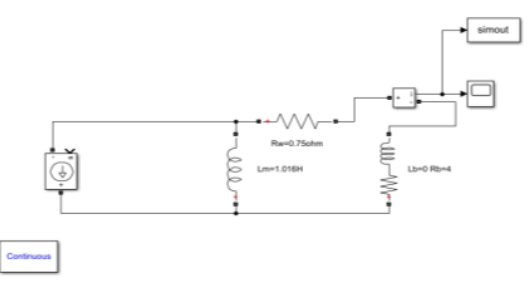

Fig.8.CT equivalent circuit

\section{FACTOR AFFECTING CT OPERATION}

There are various factors below which are considered during CT operation

\subsection{Burden}

(a) By varying resistance/burden on the secondary side we get this DC Offset values:

\section{h2(120Hz)}

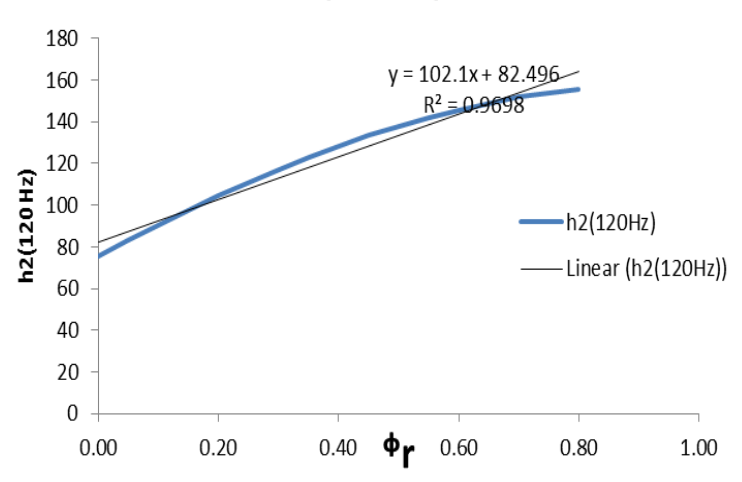

Fig. $6.2^{\text {nd }}$ harmonic frequency component vs Remenence flux

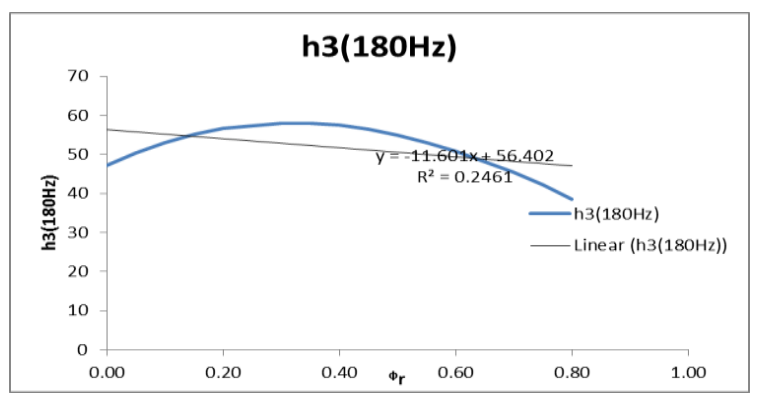

Fig.7.3 ${ }^{\text {rd }}$ harmonic frequency component vs Remenence flux

For DC offset the value of flux is linearly increases w.r.t. flux after certain offset.For fundamental its again same with certain offset but for 3rd its increases up to certain point and

\begin{tabular}{|c|c|c|c|}
\hline Switch & R or Burden & C.B. & DC offset \\
\hline 1 & 0.001 & 1 & $1.0316 \mathrm{E}-07$ \\
\hline 1 & 0.01 & 1 & $2.57 \mathrm{E}-06$ \\
\hline 1 & 0.1 & 1 & 0.000196 \\
\hline 1 & 1 & 1 & 0.018 \\
\hline 1 & 10 & 1 & 0.9951 \\
\hline 1 & 100 & 1 & 1.5805 \\
\hline 1 & 1000 & 1 & 0.3131 \\
\hline 1 & 0.001 & 0 & 0.0263 \\
\hline 1 & 0.01 & 0 & 0.1441 \\
\hline 1 & 0.1 & 0 & 1.314 \\
\hline 1 & 1 & 0 & 15.504 \\
\hline 1 & 10 & 0 & 163.307 \\
\hline 1 & 100 & 0 & 9.9001 \\
\hline 1 & 1000 & 0 & 1.953 \\
\hline 0 & 0.001 & 1 & 13.1079 \\
\hline 0 & 0.01 & 1 & 13.1079 \\
\hline 0 & 0.1 & 1 & 13.1079 \\
\hline 0 & 1 & 1 & 13.1079 \\
\hline 0 & 0.001 & 0 & 49.9413 \\
\hline 0 & 0.01 & 0 & 49.9413 \\
\hline 0 & 0.1 & 0 & 49.9413 \\
\hline 0 & 1 & 0 & 49.9413 \\
\hline 0 & 10 & 0 & 49.9413 \\
\hline 0 & 100 & 0 & 49.9413 \\
\hline & & & \\
\hline
\end{tabular}




\begin{tabular}{|c|c|c|c|}
\hline 0 & 1000 & 0 & 49.9413 \\
\hline 0 & 10 & 1 & 13.1079 \\
\hline 0 & 100 & 1 & 13.1079 \\
\hline 0 & 1000 & 1 & 13.1079 \\
\hline
\end{tabular}

(b) BY using FFT analysis tool of Powergui, the analysis of dc offset for various burden and switching position for the given simulation in MATLAB for CT saturation.

\begin{tabular}{|c|c|c|c|c|c|c|c|c|c|}
\hline \multirow{3}{*}{ Switch } & \multirow{3}{*}{ C.B. } & \multirow{3}{*}{ Burden } & \multicolumn{6}{|c|}{ DC } & \multirow{14}{*}{$\begin{array}{l}\text { Rated } \\
\text { burden } \\
\text { at rated } \\
\text { current } \\
\text { of } 5 \mathrm{~A}\end{array}$} \\
\hline & & & \multicolumn{2}{|c|}{ Scope 1} & \multicolumn{4}{|c|}{ Scope 2} & \\
\hline & & & Current & CT flux & $\mathrm{I}(\mathrm{pu} / 25 \mathrm{VA})$ & $2^{\text {nd }}$ & $4^{\text {th }}$ & $5^{\text {th }}$ & \\
\hline 1 & 1 & $\begin{array}{c}0 . \\
1\end{array}$ & $\begin{array}{c}0.00014 \\
9\end{array}$ & 2.593 & 0.2191 & 1010 & 362.8 & 271.2 & \\
\hline 0 & 1 & $\begin{array}{l}0 . \\
1\end{array}$ & 0.01768 & $\begin{array}{c}1.26 \mathrm{E}+0 \\
5\end{array}$ & 25.98 & 868400 & $\begin{array}{c}2.97 \mathrm{E}+0 \\
5\end{array}$ & $\begin{array}{c}2.17 \mathrm{E}+0 \\
5\end{array}$ & \\
\hline 1 & 0 & $\begin{array}{l}0 . \\
1\end{array}$ & 0.08744 & 2123 & 128.5 & 1021 & 368.5 & 275.7 & \\
\hline 1 & 1 & 1 & 0.1136 & $\begin{array}{c}2.35 \mathrm{E}+0 \\
4\end{array}$ & 166.9 & 8748 & 2995 & 2236 & \\
\hline 0 & 1 & 1 & 0.1091 & $\begin{array}{c}7.76 \mathrm{E}+0 \\
5\end{array}$ & 161 & $\begin{array}{c}8.68 \mathrm{E}+0 \\
5\end{array}$ & $\begin{array}{c}2.97 \mathrm{E}+0 \\
5\end{array}$ & $\begin{array}{c}2.17 \mathrm{E}+0 \\
5\end{array}$ & \\
\hline 1 & 0 & 1 & 0.08752 & $\begin{array}{c}2.29 \mathrm{E}+0 \\
5\end{array}$ & 128.6 & 8865 & 3054 & 128.6 & \\
\hline 1 & 1 & $\begin{array}{l}1 \\
2 \\
\end{array}$ & 0.1136 & $\begin{array}{c}2.65 \mathrm{E}+0 \\
4 \\
\end{array}$ & 166.9 & $\begin{array}{c}1.56 \mathrm{E}+0 \\
5\end{array}$ & $\begin{array}{c}1.18 \mathrm{E}+0 \\
5\end{array}$ & $\begin{array}{c}4.19 \mathrm{E}+0 \\
5\end{array}$ & \\
\hline 0 & 1 & $\begin{array}{l}1 \\
2\end{array}$ & 0.1095 & $\begin{array}{c}7.79 \mathrm{E}+0 \\
5\end{array}$ & 161 & $\begin{array}{c}8.68 \mathrm{E}+0 \\
5\end{array}$ & $\begin{array}{c}2.97 \mathrm{E}+0 \\
5\end{array}$ & $\begin{array}{c}2.17 \mathrm{E}+0 \\
5\end{array}$ & \\
\hline 1 & 0 & $\begin{array}{l}1 \\
2 \\
\end{array}$ & 0.08751 & $\begin{array}{c}6.91 \mathrm{E}+0 \\
5 \\
\end{array}$ & 128.6 & $\begin{array}{c}1.31 \mathrm{E}+0 \\
5 \\
\end{array}$ & $\begin{array}{c}6.94 \mathrm{E}+0 \\
5 \\
\end{array}$ & $\begin{array}{c}1.01 \mathrm{E}+0 \\
5 \\
\end{array}$ & \\
\hline & & & & & h11/h7 & $\begin{array}{c}8.66 \mathrm{E}+0 \\
0\end{array}$ & $\begin{array}{c}8.26 \mathrm{E}+0 \\
0\end{array}$ & $\begin{array}{c}8.24 \mathrm{E}+0 \\
0\end{array}$ & \\
\hline & & & & & h15/h11 & $\begin{array}{c}1.78 \mathrm{E}+0 \\
1\end{array}$ & $\begin{array}{c}3.94 \mathrm{E}+0 \\
1\end{array}$ & $\begin{array}{c}1.87 \mathrm{E}+0 \\
2\end{array}$ & \\
\hline
\end{tabular}

From above table we observe the different component present in the DC offset with different frequencies.

\section{STUDY OF FACTOR AFFECTING CURRENT TRANSFORMER OPERATION IN SATURATION POINT OF VIEW}

The maximum dc component value of a fault occurs when the instantaneous voltage is zero, which is make the primary current unsymmetrical, and then results shorter CTs saturation. Then the dc component will decay according to the time constant of the primary power system, larger time constant will result in the longer decaying process, and then longer CT saturation period.

The CTs have the lowest burden and Rct show the best performance and they have large time to saturation. By investigate the effect of flux on the CT, where it was found that the increase of flux above a certain limit leads to saturation, therefore we observed the following factors

- Turns ratio

- Burden

- Hysteresis

- Asymmetry in current

\subsection{Effect of turns ratio}

\section{Change in Isec w.r.t. CT ratio $(2000 / 5$,} $1000 / 5,200 / 5)$

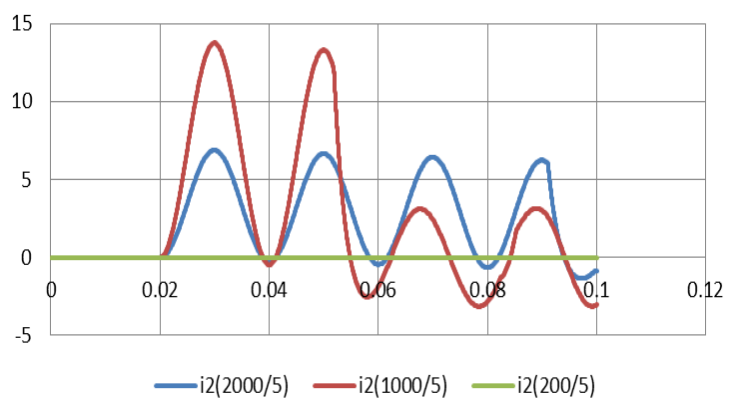

The primary and secondary currents are stated as a ratio such as $200 / 5$.

With a 200/5 ratio CT, 200A flowing in the primary winding will outcome in 5A flowing in the secondary winding, delivered the correct rated burden is connected to the secondary winding. Increasing the turn's ratio with the secondary will increase the accuracy and Burden rating. However, decreasing the turn's ratio with the secondary will degrade the accuracy and burden rating from the simulation outputs illustrated in Fig,

Published By: 
It is clear that at 2000:5 turns ratio time to saturation is approximately $0.09 \mathrm{~S}$ while at $1000: 5$ turns ratio time to saturation decreases to approximately $0.05 \mathrm{mS}$.

\subsection{Effect on Burden}

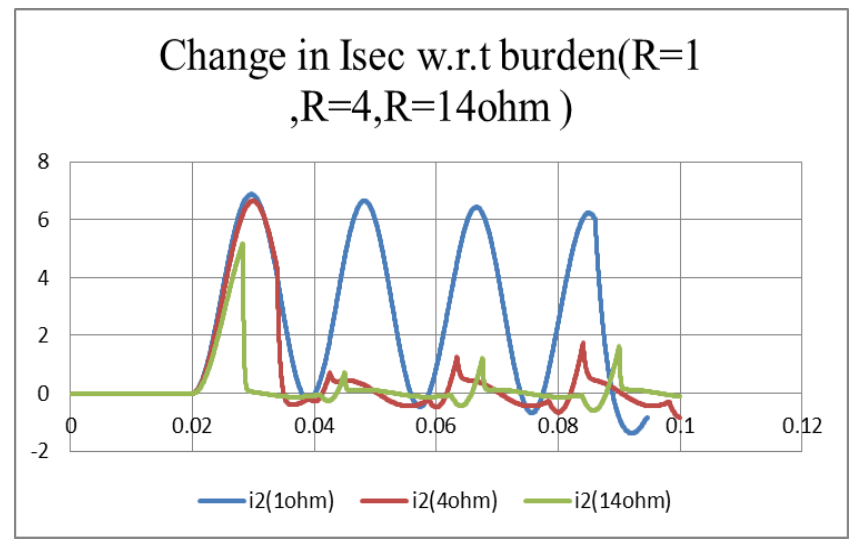

From the simulation results shown in Figure. It is clear that at 4 ohm burden resistance the time to saturation is approximately $0.04 \mathrm{~S}$. While at $14 \mathrm{ohm}$ burden, the time to saturation decreases to approximately $0.022 \mathrm{~S}$.

\subsection{Effect of Hysteresis}

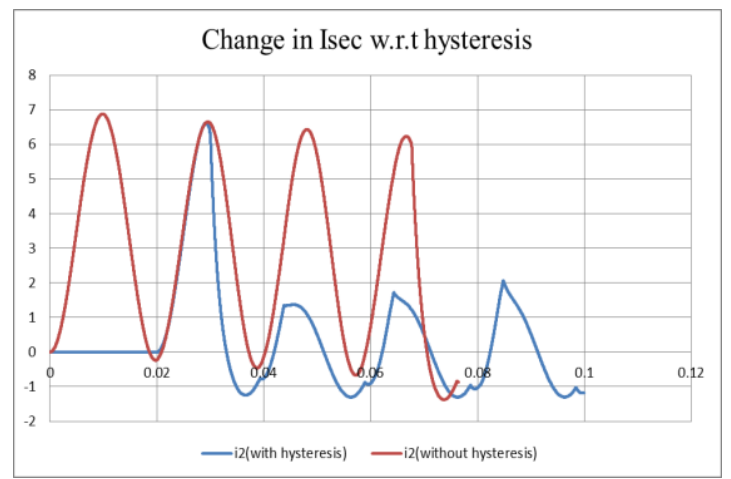

3.4 Effect of Hysteresis for different burden

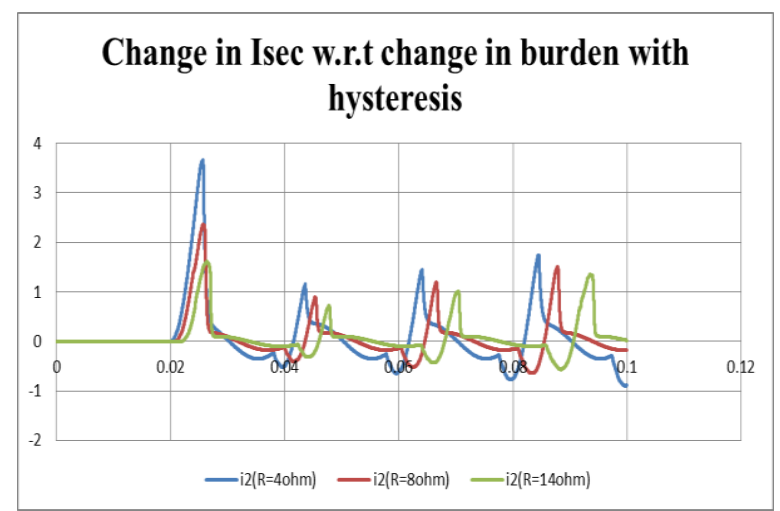

From the simulation results shown in Figure, It was found that the Time to saturation for secondary current without hysteresis is approximately $0.07 \mathrm{~S}$. However with hysteresis only is approximately $0.03 \mathrm{~S}$ and for Figure, the time to saturation is approximately $0.02 \mathrm{~s}$.
Effect of asymmetry current

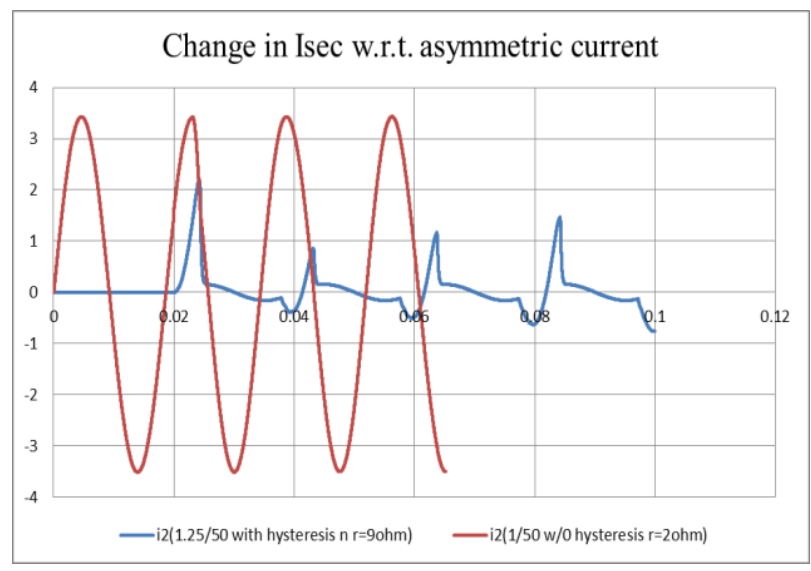

The dc component of an asymmetrical current is increase the flux in the CT. When the dc offset is at a maximum, the CT flux can potentially increase to $1+\mathrm{X} / \mathrm{R}$ times the flux resulting from the sinusoidal, or non-offset component, where $\mathrm{X}$ and $\mathrm{R}$ are the primary system reactance and resistance to the point of the fault.

\section{CASE STUdY}

Simulation for c400 CT with burden of 4ohm and 100VA (2000/5) CT saturation as per simplified model given
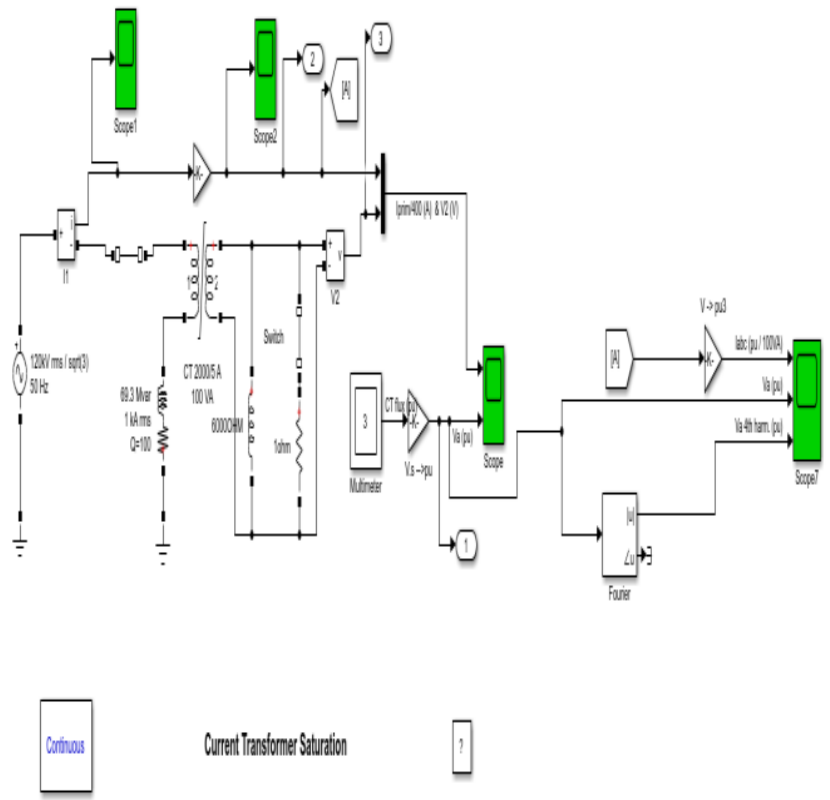

For Normal conditions the current shows following response:

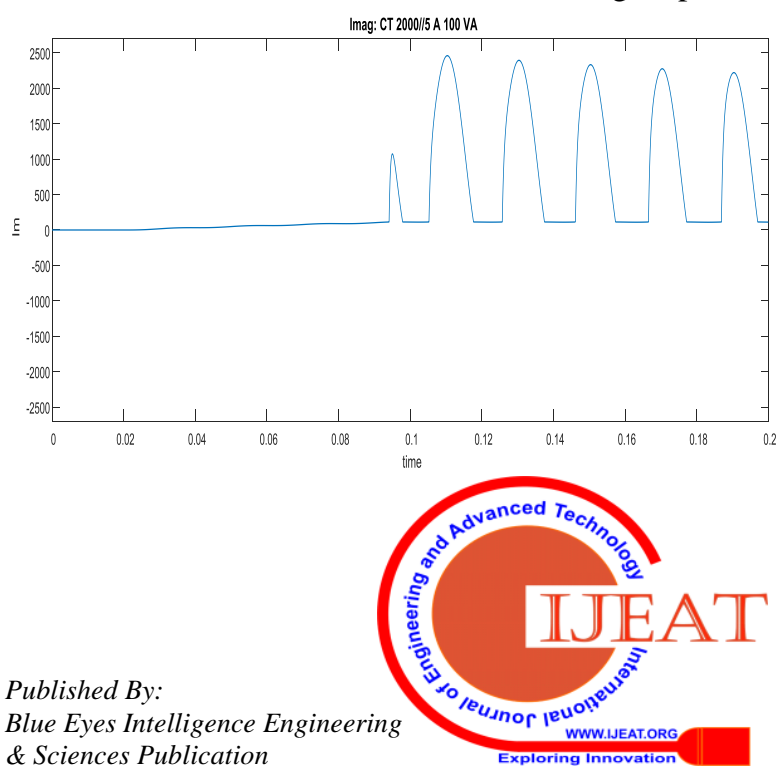




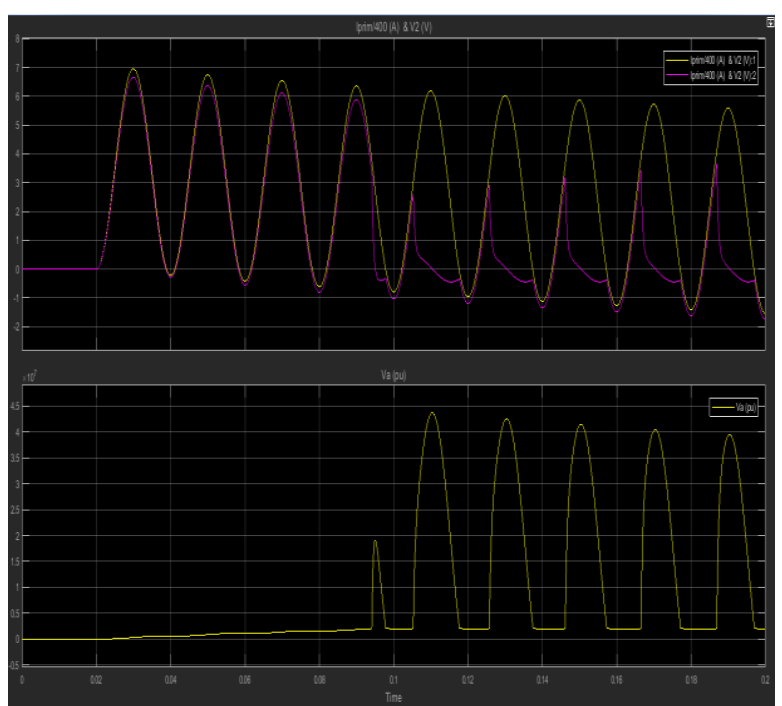

Fig.9.For Normal conditions the current without hysteresis and burden

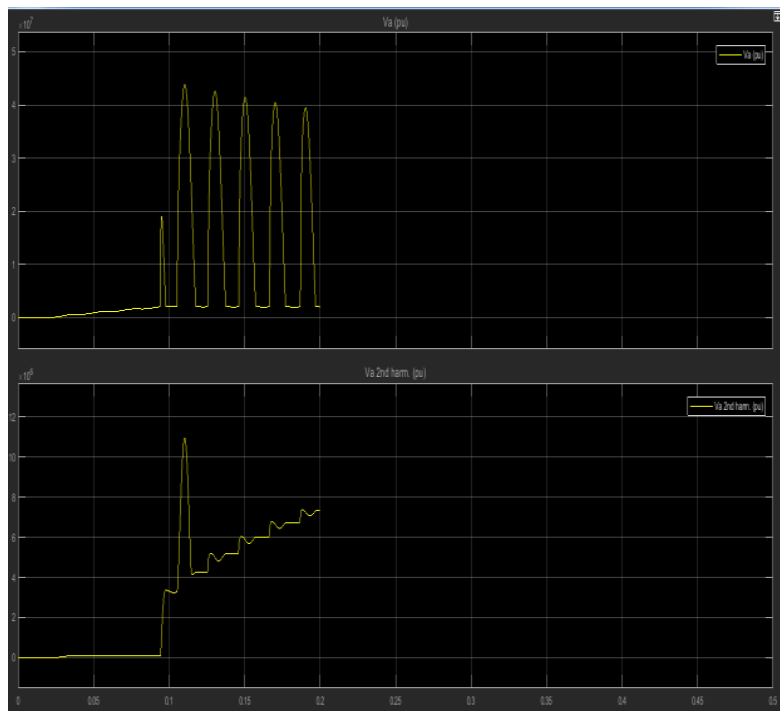

Fig.10.For Second harmonics of current without hysteresis and burden

For hysteresis conditions the current shows following response:

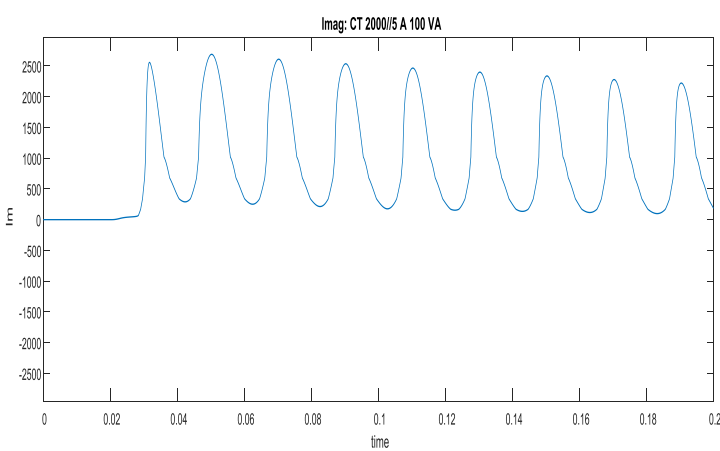

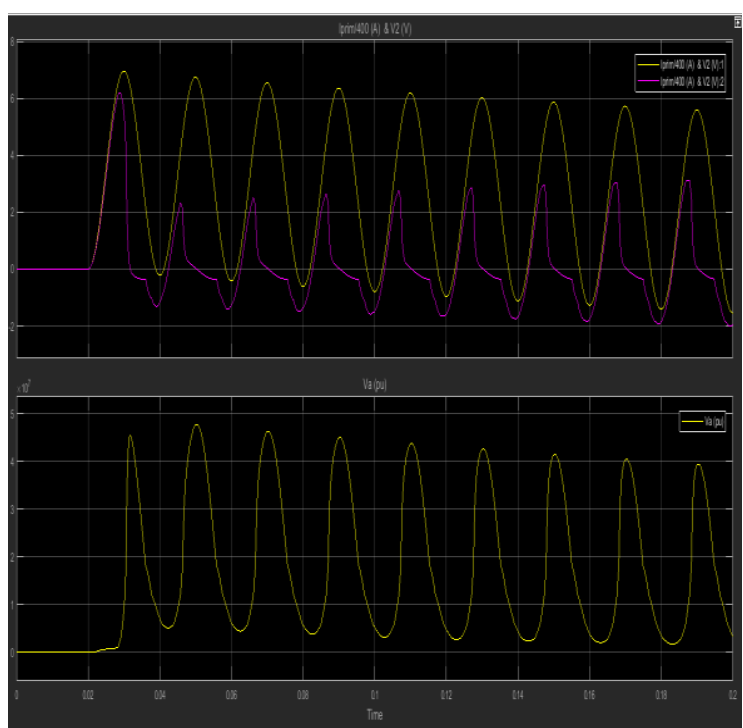

Fig.11.For abnormal operation of current with hysteresis and burden

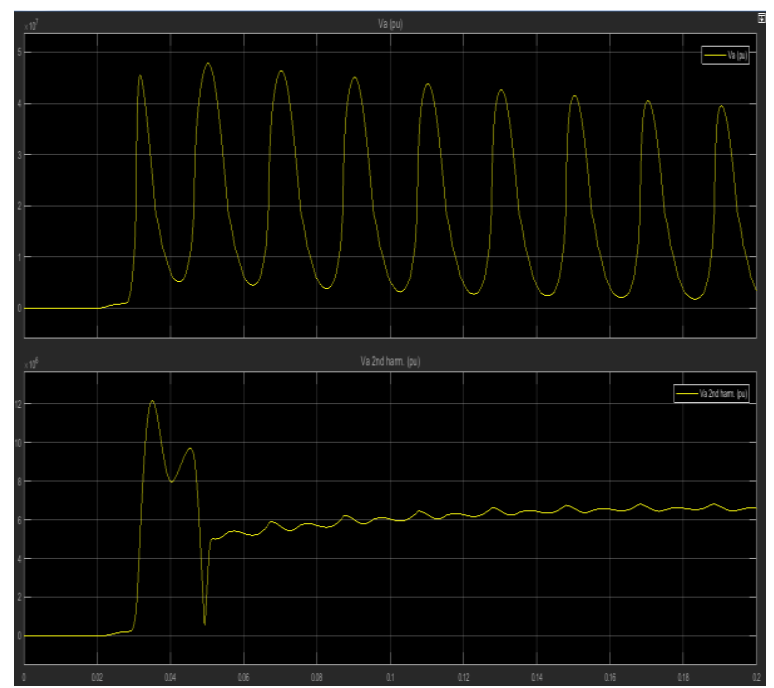

Fig.12.For Second harmonics of current with hysteresis and burden

For without saturation, current through the core i.e. magnetizing current flow is much smaller compare to the magnetizing current considering hysteresis.

For without saturation, 2nd harmonic current is present for lesser time compare to considering hysteresis.

\section{Published By:}

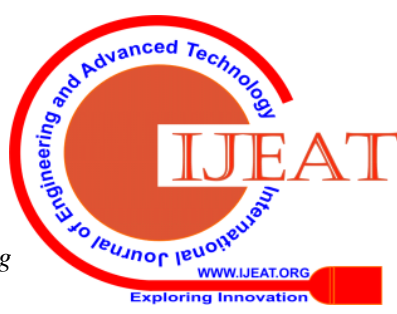




\section{ALGORITHM}
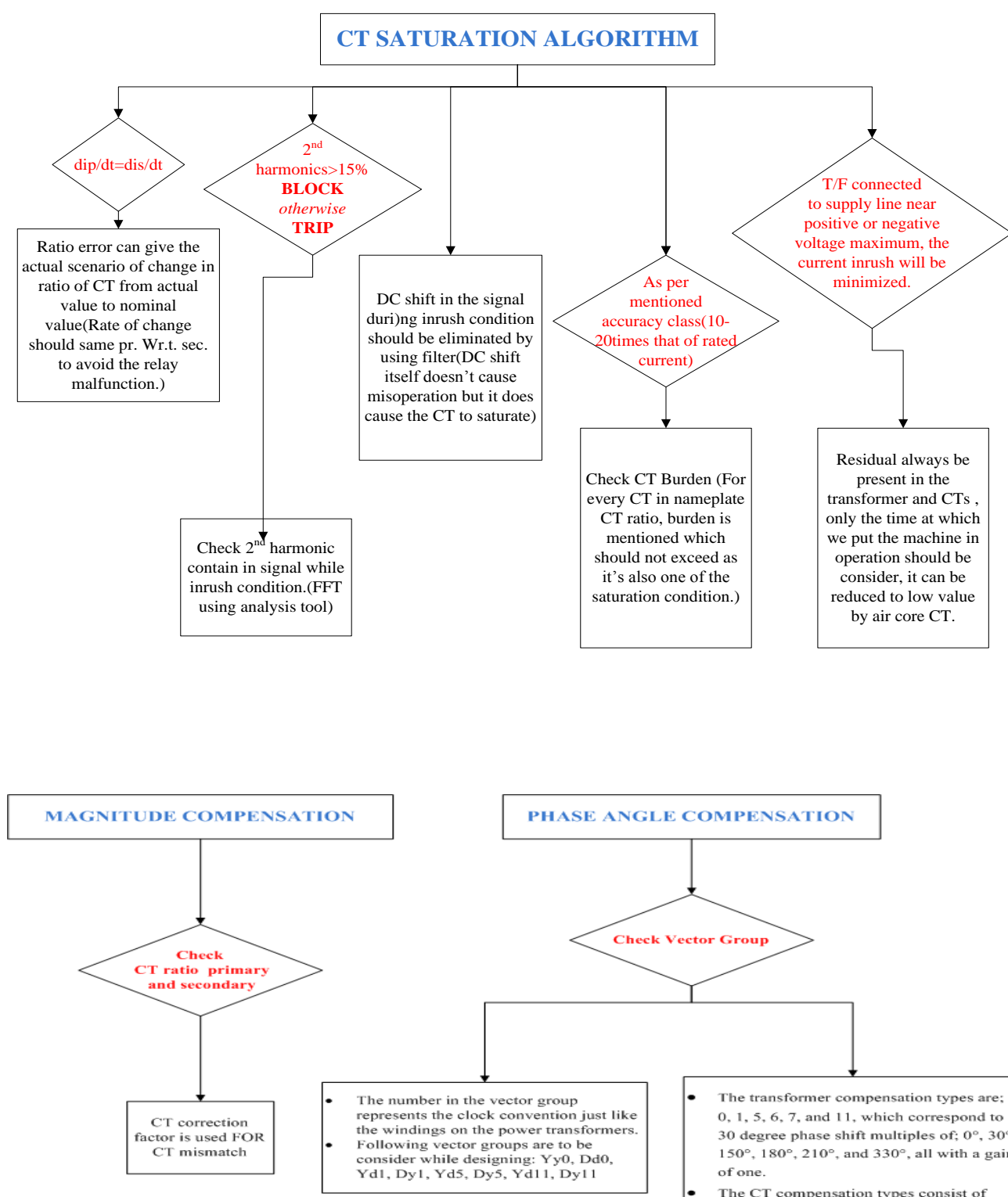
$0,1,5,6,7$, and 11 , which correspond to , $1,5,6,7$, and 11, which cons $150^{\circ}, 180^{\circ}, 210^{\circ}$, and $330^{\circ}$, all with a of one.

- The CT compensation types consist of those compensation types listed above and types 13, 17, 19, and 23. Type 13, 17, 19 and 23 correspond to 30 degree phase shif multiples of $30^{\circ}, 150^{\circ}, 210^{\circ}$, and $330^{\circ}$ but with a magnitude gain of $1 / \sqrt{3}$. 


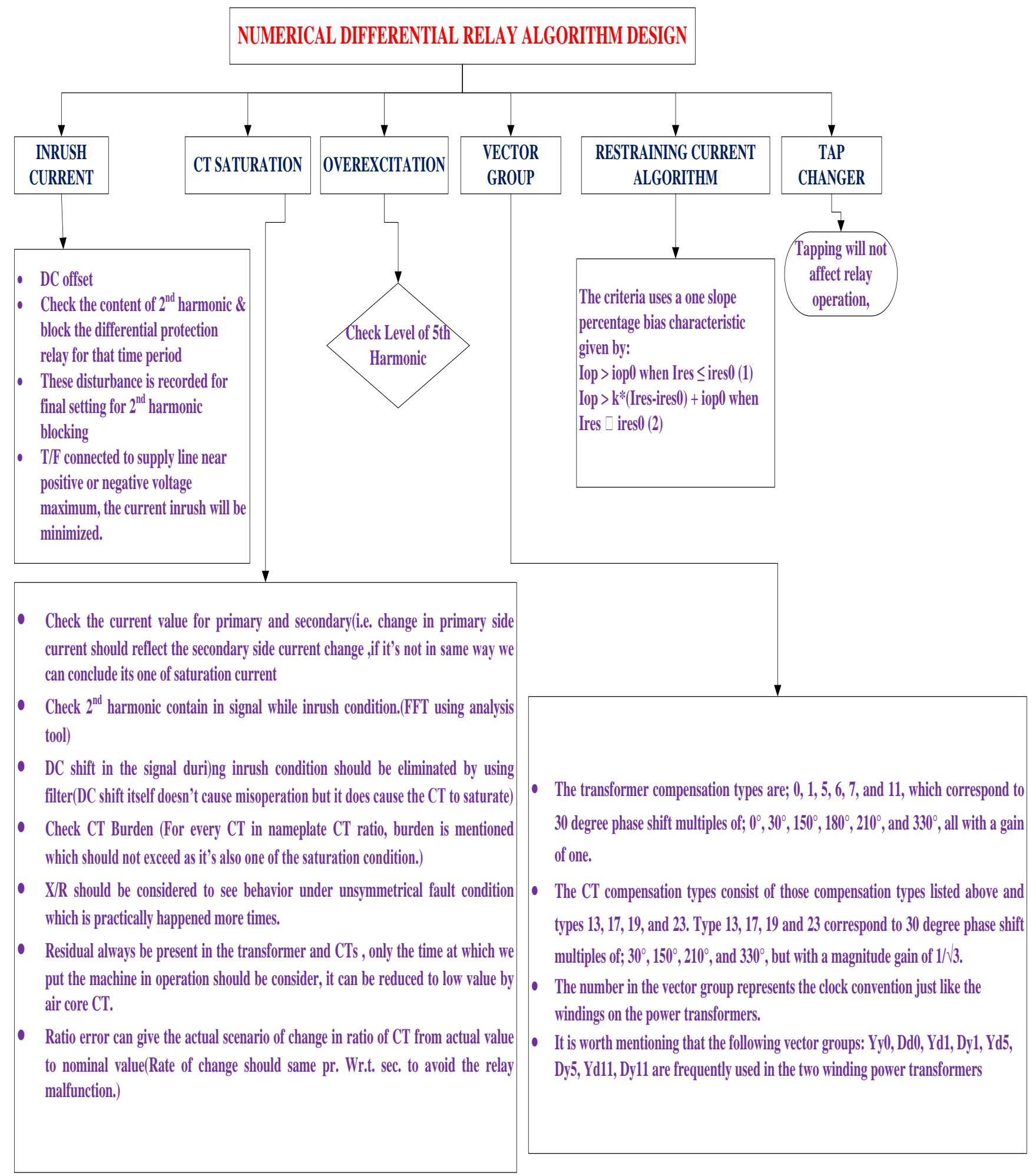




\section{CONCLUSION}

For design of algorithm for numerical differential relay we should consider three factors basically $\mathrm{Ct}$ saturation. Inrush current \& Vector group of Transformer. By investigating the effect of turns ratio, hysteresis, Asymmetry in current value and most important burden of CT above a certain limit leads to saturation. When the remnant flux is extremely high, the core will reach the saturation almost immediately, especial when the burden is high. CTs that have lowest ratio, they are the fastest to saturation.. 2nd harmonic component measurement will give us condition of CT saturation and inrush current by using FFT analysis. For the Vector group we must check the CT connection type and apply correct CT correction factor.

\section{REFERENCES}

[1] Dr. Juergen Holbach, Siemens PT\&D "Modern Solutions to Stabilize Numerical Differential Relays for Current Transformer Saturation during External Fault"

[2] "Guide For The Application Of Current Transformers Used For Protection Relaying Purposes, 1996.’'IEEE Std. C37.110

[3] Piotr Sawko Wroclaw University of Technology, Faculty of Electrical Engineering "Impact of Secondary Burden and X/R Ratio on CT Saturation"

[4] Omar.G.Mrehel Khaled Esmail. SH.Ghambirlou Mahmud .M. Alforjani, EEE Dept., University of Tripoli "Investigating Factors Affecting CT Saturation Using MATLAB" 1st Conference of Industrial Technology ( CIT2017)

[5] Badri Ram ,D N Vishwakarma, "Power system protection and switchgear"

[6] Fallahi, N. Ramezani, I. Ahmadi "Current Transformers' Saturation Detection and Compensation Based on Instantaneous Flux Density Calculations", Online ISSN 1848-3380

[7] R. P. Pandey, Dr. R. N. Patel PG Student [PSE], Professor Department of EEE, SSTC Bhilai Chhattisgarh, India"A CT Saturation Detection Algorithm Using Secondary Current Third Difference Function" (C) 2014 IJEDR | Volume 2, Issue 2 | ISSN: 2321-9939

\section{Authors Profile}

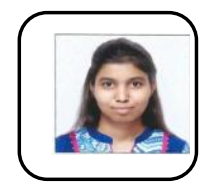

Pooja Dudhal M.Tech Student at department of Electrical Engineering, VJTI, Mumbai, India, Electrical power system. She is working as project trainee at L\&T electrical \& automation, Powai, Mumbai under EDDC department.pooja.dudha195@gmail.com

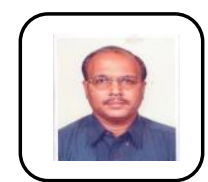

Prof.H.B.Chaudhari Above 7+ Yrs. of Experience in High Voltage, Networks, Microprocessor. Presently working as Associate Professor with VJTI, Mumbai MOU- VJTI Siemens HV Lab development, Joint testing Joint training programs MOU-Samudra institute of maritime studies,Training Marine engineers MOU-Anglo Eastern maritime training center Mumbai.

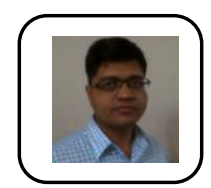

Vipin Mishra Above 12 Yrs. of Experience in Embedded product Development. Presently working as Project manager with L\&T EBG, Powai , Mumbai. Good knowledge of embedded devices, Experience in ARM architecture, Experience in
Protection Relay Development, Experience in Device driver development and debugging. Worked on Self power, Feeder, Motor and transformer protection relay.

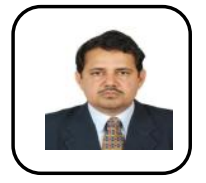

Bhanwar Lal Bishnoi (BLB),SMIEEE,MLE ${ }^{5 n}$ ,MIE,C.Eng, 22 Years of Core R\&D experience on Electronics New Technology Introduction (NTI) \& Product Design \& Development ( NPI ), Team Management and Program Management. Electronic Trip Units (ETU's -ACB/MCCB/GFCI/AFCI ), Protection Relays IEC61850 (Motors/Feeders/Transformers), Electronic Energy Meters ,Smart Energy Metering Solutions, Power Electronics Products eg. Inverters, Solar Micro Inverters , Industrial Drives , IoT Complete Eco System Design \& Development etc. Senior Member of IEEE (SMIEEE), GE-6 $\sigma \mathrm{GB} / \mathrm{EIT}-\mathrm{RP}$ $\&$ Holding more than 35 Patents already granted so far in my Career of $\sim 22$ Years. Received GE Energy - Industrial Solutions "Management Award in 2009". 